\title{
How to disseminate knowledge and skills from using a tailored simulation game
}

\author{
M. Pankakoski \\ Dept. of Industrial Management, Helsinki University of \\ Technology \\ P.O. Box 9500, 02015 TKK, Finland, tel. +358-9-451 3976, fax \\ +358-9-451 3665, e-mail: matleena.pankakoski@hut.fi
}

\begin{abstract}
Today's organisations live in the middle of a rapid change. Therefore, it is essential to create and spread new methods and skills in order to support selfdirected learning and development activities in work organisations. This article focuses on spreading of methodological competencies of using a tailored, social simulation game called the Work Flow Game, which has proved very effective for business process development. Experiences of a learning environment based on a cluster of organisations are presented. The aim of the cluster was to develop and test the Work Flow Game, and to disseminate skills and knowledge from using simulation games to the participating pilot organisations so that the method could be used independently. In addition, another promising training model is presented and some preliminary results are discussed.
\end{abstract}

\section{Keywords}

Dissemination of development methods, Work Flow Game, organisation cluster 


\section{INTRODUCTION}

In today's continuously changing business environment, it is not enough to master the product design, technology, marketing, production and delivery processes as such. Work processes and the ways of action are being reshaped, and both individuals, teams and the organisations as a whole face new learning challenges. In order to stay competitive, organisations need to develop new competencies in terms of self-directed learning and organisation development. Several case-based experiences show that a process development method called the simulation game* is a very useful development method for both production systems and administrative application areas (e.g. Forssén-Nyberg \& Hakamäki 1996; Haho, in this volume; Smeds 1996; Piispanen \& al. 1996, Ruohomäki 1995). In the Work Flow Game, three key factors of organisation development are combined: improving (or re-engineering) work processes, experiential learning and participative design.

To achieve long-term organisational change effects, there is an evident need to apply methods like the Work Flow Game to various work organisations and processes. Yet, the use of the Work Flow Game has been typically based on individual development projects, in which an outside consultant or researcher has acted as a change agent and the methodological expert. As a consequence, spreading of methodological competencies and extensive utilisation of the Work Flow Game have been slow and the development work has usually focused only on certain restricted areas within the organisation.

\section{HOW TO SOLVE THE DISSEMINATION PROBLEM?}

The situation described above presents the traditional problem of disseminating knowledge, methods, best practices, and successful experiences beyond the pilot projects. Training, case examples, site visits and publications present ways of solving this problem, but results, however, have often been disappointing. (Gustavsen 1987.) The dissemination problem can be discussed in relation to the volume of dissemination and the effectiveness of the interventions (Figure 1). Information campaigns, publications and standard training reach a great number of

* The simulation game focused on this article is called the "Work Flow Game" (Piispanen \& al. 1996, Ruohomäki 1995). This simulation game type has also been called a "participative simulation game" (Forssén-Nyberg \& Hakamäki 1996), "tailored simulation game" (Smeds 1996), and "social simulation game" (Smeds, in this volume). There are some methodological differences between these simulation game variations, but the basic innovation, the use of tailored, social simulation games for participative development of work processes, is similar in all variations. 
organisations and their people, but that does not guarantee a real change process, i.e. implementing new ways of action, and sharing knowledge and methods in a wider organisational context. Individual development projects, which are based on wide participation of different professional groups, are likely to give better results, but such projects require a lot of time, financial and human and resources. (Saarela 1991.)

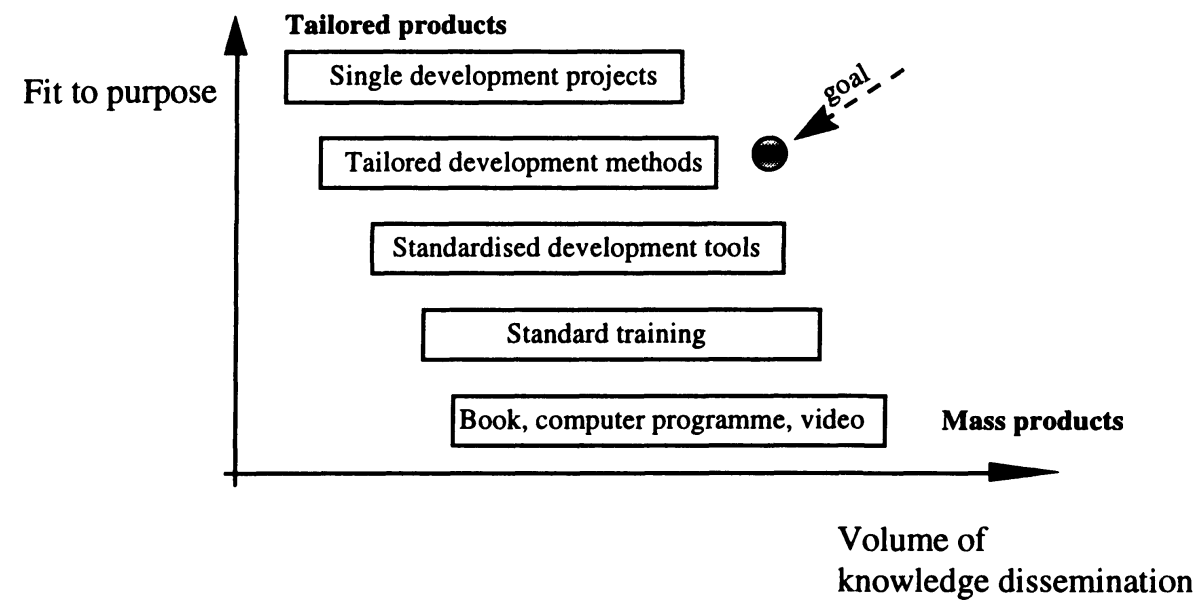

Figure 1. Tailored development methods can be disseminated and they fit the purpose.

There is a challenge to create tailored development procedures and methods, so that several organisations can be involved in development projects at the same time by tailoring the procedures and methods for their individual needs and contexts. One of the main characteristics of the Work Flow Game is that it is always tailored to the specific needs of an organisation. This can be regarded as being its methodological strength and weakness at the same time. Process development requires tailor-made, context-bound development methods, but disseminating and implementing of a tailored knowledge product is much more complicated than a standard development tool.

Perhaps the best known example of trying to solve the dissemination problem is the Swedish LOM-programme (LOM is an abbreviation of the Swedish terms for Leadership, Organisation and Codetermination), which was based on creating organisation clusters and networks, and using democratic dialogue and dialogueconferences as a means of getting different organisations and interest groups working together (Engelstad \& Gustavsen 1993). The literature concerning learning organisations also presents possible solutions to this problem, such as benchmarking, cross-learning best practices, and knowledge sharing through common experience databases. (e.g. Marquardt 1996.) 
In the LOM-programme, networks were based on organisation clusters. In the Finnish literature, a concept of "Cluster development" has been used to describe development projects, in which representatives of a few organisations work together in terms of organisation development. The aim of such clusters is usually learning from others, working on common objectives or themes, or developing and learning new working models or methods that are interesting for all participants. Different types of cluster development can be identified: thematic, regional, field of business/way of action based, method based and experience sharing. (Laitinen \& al. 1996; Pankakoski 1996.) This article presents a cluster that was characterised by combining training and organisation development into meaningful learning at work, testing and disseminating a new process development method, and having a few very different organisations working together.

\section{ORGANISATION CLUSTER AS THE LEARNING ENVIRONMENT OF THE SIMULATION GAME}

The cluster project presented in this article was carried out as a part of the Finnish National Productivity Programme (1993-). In order to test, study, further develop and disseminate the Work Flow Game method in a few different organisations at the same time, a method-based cluster was established in early 1995 . Spreading of knowledge was defined at two levels: 1) developing work processes by using the Work Flow Game in the pilot organisations and 2) using the new methodological competencies independently of the original projects by the pilot organisations. Achieving results at level two was seen especially challenging. The development projects and learning the method were supported by common training day in each main phase of the development porcess. The role of the training was to support the execution of the pilot projects and to give a theoretical background for understanding the logic and different possibilities of using the Work Flow Game method.

There were five organisations in the cluster representing four different lines of business: a vocational training organisation, a ministry, an industrial company (chemical industry) and two insurance companies. The insurance companies belonged to the same company group, so they were not competitors and could thus openly work together. In order to promote the main principles of the game method, participative development and learning together, the learning unit of each participating organisation was a planning group. The planning groups were based on wide representation of different professional groups and hierarchical levels of each organisation. Each was to take part in the training days and then use the game method in their development projects with the assistant of the researchers.

The planning of the simulation game day was instructed in common training days, which were built upon the phases of the game method (Figure 2). In the cluster model, the training days were always followed by fieldwork in participating organisations so that the theory could be put into practice immediately. In each 
training day, there were learning tasks that were started together and then given as homework for the pilot organisations to be completed during the fieldwork period. The idea of the learning tasks was to support and direct the development projects.

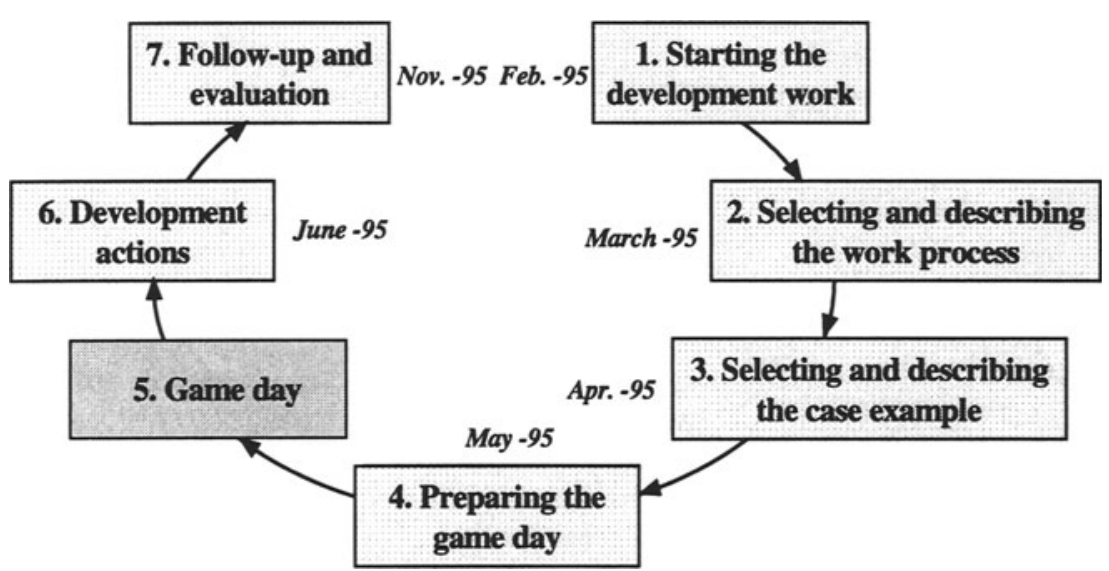

Figure 2. The cluster training proceeded according to the phases of the Work Flow Game method.

\section{EVALUATION OF THE CLUSTER}

During the cluster project, the researchers conducted action research about learning and organisational effects of the pilot projects, the experiences of simulation game participants, disseminating of methodological competencies and the cluster model as a learning environment. The objectives of the study concerning the cluster model and dissemination were firstly to evaluate the cluster a) as a means of combining organisation development and training b) as a way of developing different organisation together and c) as an environment for developing and testing the simulation game method. The second objective was to follow-up the selfdirected use of the method after the pilot projects were finished. The research was mainly a qualitative, action research oriented case study. It was based on describing, understanding and evaluating the cluster model. The most important research methods were semi-structured interviews and questionnaires. The emphasis was on process evaluation in order to direct and develop action already during the study. (Pankakoski 1996.) The main results are summed up in the following chapters. 


\subsection{Pilot projects gained results}

According to the representatives of the pilot organisations, training and organisation development were well combined. The training days structured the planning process of the simulation games, provided new information, presented the pilots with opportunities to share experiences, and offered a peaceful place and time for the planning groups to work together. The learning tasks for the fieldwork periods scheduled the planning process and supported learning of the game method. From the researchers' point of view, the organisation cluster offered a valuable environment for testing and developing the method, which showed that the game method is applicable to developing various kinds of work processes both in the public and the private sector.

Regardless of the outcome of the development actions, one should not forget that completing a development project is always an achievement as such. The reason for success in this case was a systematic approach to carry out the projects step by step. The pilot projects had a clear goal and timetable. The common training days were in the supporting role, whereas the most important work was done in the field together with the researchers. This is perhaps one of the main differences compared to some other types of clusters, where sharing experiences, discussion and co-operation play the main role, but the development actions outside the cluster meetings are solely the responsibility of the participants. (Juuti \& Varjoranta 1993, Lahtonen 1996, Naschold 1992). On the other hand, in this cluster, the participating groups were not as self-directed as they could have been without outside resources.

\subsection{Different types of organisations: pros and cons}

The main advantages of having different organisations working together concerned methodological cross-learning and sharing experiences. On one hand, different lines of business made the cluster interesting, but on the other hand it also made learning from others more difficult. Even so, having different types of organisations in the cluster was a necessity in order to reach the method development goal. A few participants felt that belonging to the cluster increased the credibility and legitimacy of the project in their own organisations. Moreover, the cluster meant a stimulating competitive position for some participants in terms of comparing one's own performance to others. Lahtonen (1996) brings up similar observations based on her study about democratic dialogue and networking in Finnish metal industry. Working together had made it easier to get started with the development projects, encouraged the participating organisations in their efforts, and created a positive social competition within the cluster.

Other shortcomings of the cluster model concerned the differences of the pilot organisations in terms of facilities for carrying out a development project as well as a lack of interaction between the pilot organisations. During the training days 
there was no time to have, for instance, mixed groups or other special interorganisational tasks. Interaction could have been increased by making more visits to other organisations, especially by participating more in the game events of others.

Only two pilot organisations had co-operation outside the cluster events. The preconditions for true co-operation include a common goal, problem or objective. The starting shot for co-operation may be a problem that is bigger than any organisation can solve alone. (Gray 1985.) In this cluster, two pilots had a common theme, labour market training, which is an excellent example of a significant social issue that requires the input of several organisations and stakeholders.

\subsection{Self-directed use of the game method got started}

The cluster was successful in spreading of methodological know-how. Firstly, all the planning groups were able to carry out one or two process development projects during the cluster by using the Work Flow Game method. Secondly, and more importantly from the viewpoint of this article, during the one year follow-up period, three organisations used the game method independently and all the pilot organisations thought they had acquired a good level of competence in terms of applying the Work Flow Game.

The new game leaders had managed well in terms of facilitating the game events. In the new simulation game projects, the method had been applied to specific organisational needs and also combined to other earlier used development methods. Yet, the main characteristics of the method were still clearly identified in the new game variations. These results show the advantages of tailored development methods.

When evaluating the dissemination or diffusion implications, attention should be paid both to the transfer of learning and continuity of actions (Baldwin \& Ford 1988). We can talk about transfer of learning concerning the three organisations that carried out new games without outside resources. A more far-reaching followup period is needed to assess the continuity of their efforts. Based on the latest interviews it could be assumed that these organisations have serious plans and good preconditions to continue utilising the game method in their future work process development projects.

Based on this case study, some critical factors for starting a self-directed use of the game method can be listed: responsible persons who have time and competence for carrying out new development projects, a conscious decision to learn and use the method as a development tool, previous experience in organisation development or using experiential learning methods and, a real need to apply the method in the work community. In future clusters, more attention should be paid to the composition of planning groups. In each group there should be persons who are responsible for organisational development tasks to ensure the dissemination of methodological knowledge. In method based clusters it is 
similarly important that all participants aim at learning the method instead of developing only a certain area. On the other hand, even a method-based cluster consists of both the method and the chosen development object. Therefore, there should also be persons who know the substance of the development area sufficiently.

The transfer of training is affected by several factors. Robinson \& Robinson (1989) present a formula for the impact of training: Learning Experience $\mathrm{x}$ Work Environment $=$ Business Results. Learning by itself will be insufficient to produce on-the-job results, if the work environment does not encourage the use of skills learnt in the training. According to the experiences of this case, two new factors could be added to the formula: the object of learning (e.g. a development method) and the ability and motivation of the participants to apply things they have learnt. The properties of the development method present the critical factor as far as disseminating knowledge and skills from organisation development are concerned. Even though tailoring the method has been emphasised, the method should be well documented and to some extent formalised so that it can be communicated to new users. Yet, the method is not to blame if potential users do not have the need, ability or organisational support for applying it.

\section{SIMNET TRAINING PROGRAMME FOR DISSEMINATING THE WORK FLOW GAME}

Five organisations participated in the simulation game cluster. In order to get much more organisations involved, a new training programme called SIMNET was started in 1996 (Teikari et al. 1995, 122). The aim of the programme is to train dozens of new simulation game experts, who are able to apply the method in their own process development projects. The programme has been designed according to the model described in this article: training days, learning tasks and field work are linked together based on the phases of the game method to form an action learning type of project (cf. Revans 1982). The main difference compared to the cluster model is that only the change agent, i.e. the game facilitator, participates in the training day instead of the whole planning group. The game facilitators are responsible for carrying out their development processes independently in their home organisations without outside change agents.

During 1996 and 1997 two SIMNET training programmes have been carried out. eleven new game facilitators from ten different organisations were trained during the first programme. The results are very promising: all participants succeeded in carrying out independently their process development projects by using the Work Flow Game. Five of them have already applied the game method to new change processes. Ten new game facilitators from eight different organisations were trained in the second programme. The first results were very good again: eight participants completed their projects during the programme, and three of them started a new development project right after the first simulation games. 


\section{CONCLUSIONS}

The cluster and the first two rounds of SIMNET prove that the method can be disseminated and used independently if instructed and supported systematically. This is encouraging in terms of national productivity efforts, for these kind of programmes reach several organisations at the same time and can be regarded as an efficient way of using development resources. Moreover, this approach is also relevant in terms of co-operation between universities and work organisations: researchers can develop and disseminate the latest methodological innovations in the area of organisation development and at the same time facilitate work communities to get more independent in their development efforts. There is a follow-up study going on about the SIMNET programme, which makes it possible to compare the effects of different knowledge sharing models of the Work Flow Game and organisational innovations in general.

\section{REFERENCES}

Baldwin, T. T. and Ford, J. K. (1988) Transfer of training: a review and directions for future research. Personnel Psychology, 41, 63-105.

Engelstad, P. and Gustavsen, B. (1993) Swedish Network Development for Implementing National Work Reform Strategy. Human Relations, 46, 2, 219 248.

Forssén-Nyberg, M. and Hakamäki, J. (1996) Development of the production using participative simulation games. Proceedings of the Ninth International Working Seminar on Production Economics, 3, Igls, Austria, February 19-23, 305-318.

Gustavsen, B. (1987) Diffusion and discussion: national strategies for changing working life and the role of democratic dialogue, in Future of work, a viewpoint of social sciences (ed. K. Eklund), NIVA, Helsinki, 16-30.

Gray, B. (1985) Conditions facilitating interorganizational collaboration. Human Relations, 38, 10, 911-936.

Juuti, P. and Varjoranta, T. (1993) Leadership, Organization and Cooperation in the Metal Industry. Study No 39 (Työpoliittinen tutkimus), Ministry of Labour, Helsinki. (in Finnish)

Lahtonen, M. (1996) Democratic dialogue in the metal industry - evaluation study. Study No 148 (Työpoliittinen tutkimus), Ministry of Labour, Helsinki. (in Finnish)

Laitinen, M., Vartiainen, M. and Pulkkis, A. (1996) Cluster development as a method for learning organisations. Aikuiskasvatus, The Finnish Journal of Adult Education, 16, 2, 93-103. (in Finnish)

Marquardt, M. J. (1996) Building the Learning Organization. McGraw-Hill, New York. 
Naschold, F. (1992) Evaluation report commissioned by the board of the LOM Programme. Arbetslivscentrum, Stockholm.

Pankakoski, M. (1996) Organisation cluster as the learning environment of the simulation game. HUT/Industrial management and work and organizational psychology. Report No 2/Otaniemi 1996. (in Finnish)

Piispanen, E., Ruohomäki, V., Pankakoski, M. and Teikari, V. (1996) The Work Flow Game - A new method for developing office work, in The Simulation and Gaming Yearbook, Vol 4: Games and Simulations to Enhance Quality Learning (eds. D. Saunders, F. Percival, and M. Vartiainen), Kogan Page, London, 85-95.

Revans, R. W. (1982) The origins and growth of action learning. Studentlitteratur, Lund.

Robinson, D. G and Robinson, J. C. (1989) Training for Impact: How to Link Training to Business Needs and Measure the Results. Jossey-Bass Publishers, San Francisco.

Ruohomäki, V. (1995) A simulation game for the development of administrative work processes, in The Simulation \& Gaming Yearbook 1995, Vol 3. (ed. D. Saunders), Kogan Page, London, 264-270.

Saarela, K. L. (1991) Promoting safety in industry: Focus on informational campaigns and participative programs. Doctoral Dissertation, Helsinki University of Technology, Laboratory of Industrial Psychology, Institute of Occupational Health, Department of Occupational Safety.

Smeds, R. (1996) Management of Enterprise Evolution. Evolution Management Principles and Methods for Learning Organizations. Acta Polytechnica Scandinavica, Mathematics, computing, and management in engineering series, No 80, Helsinki.

Teikari, V., Aaltonen, P., Jaakola, M., Koivula, A., Pankakoski, M., Piispanen, E., Ruohomäki, V. and Timonen, K. (1995) Simulation games and process measures - case experiences from the field. Productive Office (Keto) -project, final report, Helsinki University of Technology, Laboratory of Industrial Psychology, Espoo. (in Finnish)

\section{BIOGRAPHY}

The author works as a researcher in the Department of Industrial Management at Helsinki University of Technology. She is a master of education and licentiate of technology. At present she is preparing her doctoral dissertation about the knowledge sharing models of organisational innovations. Her special fields are development of business processes and teams, social simulation games, and training models based on open learning environments. 